\title{
FINITE DIFFERENCE SOLUTION \\ OF RADIATION EFFECTS ON MHD \\ UNSTEADY FREE-CONVECTION FLOW \\ OVER VERTICAL PLATE WITH VARIABLE SURFACE TEMPERATURE
}

\author{
M. A. ABD EL-NABY, ELSAYED M. E. ELBARBARY, \\ AND NADER Y. ABDELAZEM
}

Received 20 May 2002 and in revised form 24 September 2002

\begin{abstract}
An analysis is performed to study radiation effects on magnetohydrodynamic (MHD) unsteady free-convection flow past a semi-infinite vertical plate with variable surface temperature in the presence of transversal uniform magnetic field. The boundary layer equations are transformed into a linear algebraic system by an implicit finite-difference method. A parametric study is performed to illustrate the influence of radiation parameter, magnetic parameter, and Prandtl number on the velocity and temperature profiles. The numerical results reveal that the radiation has significant influences on the velocity and temperature profiles, skin friction, and Nusselt number. The results indicate that the velocity, temperature, and local and average skin friction increase as the radiation parameter increases, while the local and average Nusselt numbers decrease as the radiation parameter increases.
\end{abstract}

\section{Introduction}

The most common type of body force, which acts on a fluid, is due to gravity so that the body force can be defined as in magnitude and direction by the acceleration due to gravity. Sometimes, electromagnetic effects are important. The electric and magnetic fields themselves must obey a set of physical laws, which are expressed by Maxwell's equations. The solution of such problems requires the simultaneous solution of the equations of fluid mechanics and of electromagnetism. One special case of this type of coupling is the field known as magnetohydrodynamic (MHD). 


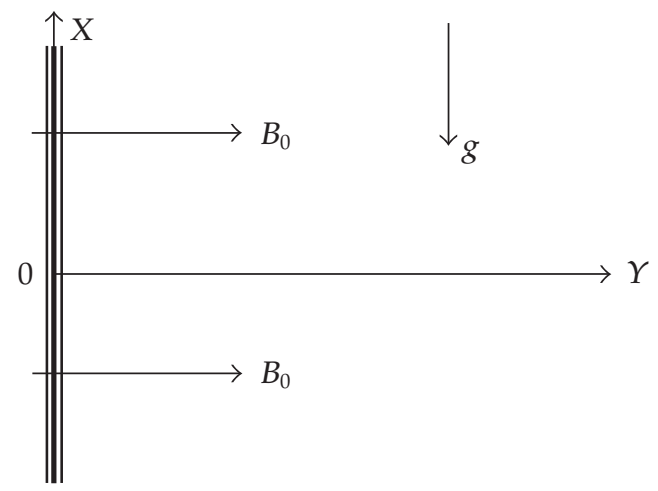

FIGURE 1.1. Sketch of the physical model.

The effect of radiation on MHD flow and heat transfer problems has become industrially more important. Many engineering processes occur at high temperatures, and the knowledge of radiation heat transfer has become very important for the design of pertinent equipment. Nuclear power plants, gas turbines, and various propulsion devices for aircraft, missiles, satellites, and space vehicles are examples of such engineering processes. At high operating temperature, radiation effect can be quite significant.

Takhar et al [15] studied the radiation effects on MHD free-convection flow of a gas past a semi-infinite vertical plate. The radiation effect on heat transfer over a stretching surface has been studied by Elbashbeshy [2]. Thermal radiation and buoyancy effects on MHD free convective heat generating flow over an accelerating permeable surface with temperature-dependent viscosity has been studied by Seddeek [11]. Recently, Ghaly and Elbarbary [4] have investigated the radiation effect on MHD free convection flow of a gas at a stretching surface with a uniform free stream. In all the above investigations, only steady-state flows over semi-infinite vertical plate have been studied. The unsteady freeconvection flows over vertical plate have been studied by Gokhale [5], Takhar et al. [14], Muthukumaraswamy and Ganesan [8]. The problem of the effect of radiation on MHD unsteady free-convection flow has not received any attention yet. Hence, the present study is attempted.

\section{Mathematical formulae}

Consider the unsteady flow of an electrically conducting viscous fluid adjacent to a vertical plate coinciding with the plane $Y=0$, where the flow is confined to $Y>0$. A uniform magnetic field of strength $B_{0}$ is imposed along the $Y$-axis (see Figure 1.1). 
MHD equations are the usual electromagnetic and hydrodynamic equations, but they are modified to take account of the interaction between the motion and the magnetic field. As in most problems involving conductors, Maxwell's displacement currents are ignored so that electric currents are regarded as flowing in closed circuits. Assuming that the velocity of flow is too small compared to the velocity of light, that is, the relativistic effects are ignored, the system of Maxwell's equations can be written in the form [10]

$$
\begin{array}{cc}
\nabla \times \bar{B}=\mu \bar{J}, & \nabla \cdot \bar{J}=0, \\
\nabla \times \bar{E}=-\frac{\partial \bar{B}}{\partial t}, & \nabla \cdot \bar{B}=0,
\end{array}
$$

and Ohm's law can be written in the form

$$
\bar{J}=\sigma(\bar{E}+\bar{U} \times \bar{B})
$$

where $\bar{B}$ is the magnetic induction intensity, $\bar{E}$ is the electric field intensity, $\bar{J}$ is the electric current density, $\mu$ is the magnetic permeability, and $\sigma$ is the electrical conductivity. In the equation of motion, the body force $\bar{J} \times \bar{B}$ per unit volume is added. This body force represents the coupling between the magnetic field and the fluid motion which is called Lorentz force.

The induced magnetic field is neglected under the assumption that the magnetic Reynolds number is small. This is a rather important case for some practical engineering problems where the conductivity is not large in the absence of an externally applied field and with negligible effects of polarization of the ionized gas. It has been taken that $\bar{E}=0$. That is, in the absence of convection outside the boundary layer, $\bar{B}=$ $B_{0}$ and $\nabla \times \bar{B}=\mu \bar{J}=0$, then (2.2) leads to $\bar{E}=0$. Thus, the Lorentz force becomes $\bar{J} \times \bar{B}=\sigma(\bar{U} \times \bar{B}) \times \bar{B}$. In what follows, the induced magnetic field will be neglected. This is justified if the magnetic Reynolds number is small. Hence, to get a better degree of approximation, the Lorentz force can be replaced by $\sigma\left(\bar{U} \times B_{0}\right) \times B_{0}=-\sigma B_{0}^{2} \bar{U}$.

The radiating gas is said to be nongray if its absorption coefficient is dependent on wave length [12]. The equation that describes the conservation of radiative transfer in a unit volume for all wave length is

$$
\nabla \cdot \bar{q}_{r}=\int_{0}^{\infty} K_{\lambda}(T)\left(4 \pi I_{b \lambda}(T)-G_{\lambda}\right) d \lambda,
$$


where $I_{b \lambda}$ is the spectral intensity for a black body, $K_{\mathcal{\lambda}}$ is the absorption coefficient, and the incident radiation $G_{\lambda}$ is defined as

$$
G_{\mathcal{\lambda}}=\int_{\Omega=4 \pi} I_{b \lambda}(\Omega) d \Omega,
$$

where $\bar{q}_{r}$ is the radiation heat flux and $\Omega$ is the solid angle.

For an optically thin fluid exchanging radiation with an isothermal flat plate and according to (2.4) and Kirchhoff's law, the incident radiation is given by [1]

$$
G_{\lambda}=4 \pi I_{b \lambda}\left(T_{w}\right)=4 e_{b \lambda}\left(T_{w}\right)
$$

where $T_{w}$ is the average value of the porous plate temperature. Then, (2.3) reduces to

$$
\nabla \cdot \bar{q}_{r}=4 \int_{0}^{\infty} K_{\lambda}(T)\left(e_{b \lambda}(T)-e_{b \lambda}\left(T_{w}\right)\right) d \lambda
$$

Expanding $e_{b \lambda}(T)$ and $K_{\lambda}(T)$ in Taylor series around $T_{w}$ for small $(T-$ $\left.T_{w}\right)$ and substituting by the result in (2.6) reduces to

$$
\nabla \cdot \bar{q}_{r}=-4 \Gamma\left(T-T_{w}\right)
$$

where

$$
\Gamma=\int_{0}^{\infty} K_{\lambda w}\left(\frac{\partial e_{b \lambda}}{\partial T}\right)_{w} d \lambda
$$

$K_{\lambda w}=K_{\lambda}\left(T_{w}\right)$ is the mean absorption coefficient, $e_{b \lambda}$ is Plank's function, and $T$ is the temperature of the fluid in the boundary layer.

Initially, it is assumed that the plate and the fluid are at the same temperature $T_{\infty}$. At time $t \geq 0$, the plate temperature is assumed to vary with the power of the axial coordinate. It is also assumed that the fluid properties are constant except for the density variation that induces the buoyancy force.

Under the boundary layer and the Boussinesq approximations [7, 9], the unsteady two-dimensional laminar boundary layer free convective 
flow is governed by the equations

$$
\begin{gathered}
\frac{\partial U}{\partial X}+\frac{\partial V}{\partial Y}=0 \\
\frac{\partial U}{\partial t^{\prime}}+U \frac{\partial U}{\partial X}+V \frac{\partial U}{\partial Y}=v \frac{\partial^{2} U}{\partial Y^{2}}+g \beta\left(T-T_{\infty}\right)-\frac{\sigma}{\rho} B_{0}^{2} U, \\
\frac{\partial T}{\partial t^{\prime}}+U \frac{\partial T}{\partial X}+V \frac{\partial T}{\partial Y}=\frac{k}{\rho c_{p}} \frac{\partial^{2} T}{\partial Y^{2}}-4 \Gamma\left(T-T_{w}\right),
\end{gathered}
$$

where $U$ and $V$ are the velocity components in the $X$ and $Y$ directions, respectively, $t^{\prime}$ the time, $v$ the fluid kinematic viscosity, $g$ the acceleration due to gravity, $\beta$ the coefficient of thermal expansion, $T_{\infty}$ the temperature of the fluid far away from the plate, $\rho$ the density, $B_{0}$ the applied magnetic field, $k$ the thermal conductivity fluid, and $c_{p}$ the specific heat at constant pressure.

The initial and boundary conditions relevant to the problem are taken as

$$
\begin{gathered}
t^{\prime} \leq 0, \quad U=0, \quad V=0, \quad T=T_{\infty}, \\
t^{\prime}>0, \quad U=0, \quad V=0, \quad T=T_{\infty}+\left(T_{w}-T_{\infty}\right) X^{m} \quad \text { at } Y=0, \\
U=0, \quad T=T_{\infty} \quad \text { at } X=0, \\
U \longrightarrow 0, \quad T \longrightarrow T_{\infty} \quad \text { at } Y \longrightarrow \infty .
\end{gathered}
$$

Introducing the following nondimensional quantities:

$$
\begin{gathered}
x=\frac{X}{L}, \quad y=\frac{Y}{L} \mathrm{Gr}^{1 / 4}, \quad u=\frac{U L}{v} \mathrm{Gr}^{-1 / 2}, \quad v=\frac{V L}{v} \mathrm{Gr}^{-1 / 4}, \\
F=\frac{4 \Gamma L^{2}}{v \mathrm{Gr}^{1 / 2}}, \quad \operatorname{Pr}=\frac{v \rho c_{p}}{k}, \quad t=\frac{v t^{\prime}}{L^{2}} \mathrm{Gr}^{1 / 2}, \quad \theta=\frac{T-T_{\infty}}{T_{w}-T_{\infty}}, \\
\mathrm{Gr}=\frac{g \beta L^{3}\left(T_{w}-T_{\infty}\right)}{v^{2}}, \quad M=\frac{\sigma B_{0}^{2} L^{2}}{\mu \mathrm{Gr}^{1 / 2}},
\end{gathered}
$$

where $L$ is the length of the plate, Gr the Grashof number, Pr the Prandtl number, and $F$ the radiation parameter, we can obtain that the governing 
equations in a dimensionless form could be

$$
\begin{gathered}
\frac{\partial u}{\partial x}+\frac{\partial v}{\partial y}=0 \\
\frac{\partial u}{\partial t}+u \frac{\partial u}{\partial x}+v \frac{\partial u}{\partial y}=\frac{\partial^{2} u}{\partial y^{2}}+\theta-M u \\
\frac{\partial \theta}{\partial t}+u \frac{\partial \theta}{\partial x}+v \frac{\partial \theta}{\partial y}=\frac{1}{\operatorname{Pr}} \frac{\partial^{2} \theta}{\partial y^{2}}-F(\theta-1)
\end{gathered}
$$

The corresponding initial and boundary conditions in a nondimensional form are given by

$$
\begin{gathered}
t \leq 0, \quad u=0, \quad v=0, \quad \theta=0, \\
t>0, \quad u=0, \quad v=0, \quad \theta=x^{m} \quad \text { at } y=0, \\
u=0, \quad \theta=0 \quad \text { at } x=0, \\
u \longrightarrow 0, \quad \theta=0 \quad \text { at } y \longrightarrow \infty .
\end{gathered}
$$

\section{Solution methodology}

The unsteady, nonlinear coupled equations (2.12) with conditions (2.13) are solved by using an implicit finite-difference scheme which is discussed by Soundalgekar [13]. Consider a rectangular region with $x$ varying from 0 to 1 and $y$ varying from 0 to $y_{\max }(=6.4)$, where $y_{\max }$ corresponds to $y=\infty$ at which lies well outside the momentum and energy boundary layers. The region to be examined in $(x, y, t)$ space is covered by a rectilinear grid with sides parallel to axes with $\Delta x, \Delta y$, and $\Delta t$, the grid spacing in $x, y$, and $t$ directions, respectively. The grid points $(x, y, t)$ are given by $(i \Delta x, j \Delta y, n \Delta t)$, where $i=0(1) P, j=0(1) Q$, $\Delta x=1 / P, \Delta y=y_{\max } / Q$, and $n=0,1,2, \ldots$. The grid sizes are taken as $\Delta x=1 / 16, \Delta y=0.2$, and $\Delta t=0.05$. The functions satisfying the difference equations at the grid point are $u_{i, j}^{n}, v_{i, j}^{n}$, and $\theta_{i, j}^{n}$. The finite-difference equations corresponding to (2.12) are given by

$$
\begin{aligned}
& \frac{1}{4 \Delta x}\left(u_{i, j}^{n+1}-u_{i-1, j}^{n+1}+u_{i, j-1}^{n+1}-u_{i-1, j-1}^{n+1}+u_{i, j}^{n}-u_{i-1, j}^{n}+u_{i, j-1}^{n}-u_{i-1, j-1}^{n}\right) \\
& +\frac{1}{2 \Delta y}\left(v_{i, j}^{n+1}-v_{i, j-1}^{n+1}+v_{i, j}^{n}-v_{i, j-1}^{n}\right)=0
\end{aligned}
$$




$$
\begin{aligned}
\frac{1}{\Delta t}( & \left.u_{i, j}^{n+1}-u_{i, j}^{n}\right)+\frac{1}{2 \Delta x} u_{i, j}^{n}\left(u_{i, j}^{n+1}-u_{i-1, j}^{n+1}+u_{i, j}^{n}-u_{i-1, j}^{n}\right) \\
& +\frac{1}{4 \Delta y} v_{i, j}^{n}\left(u_{i, j+1}^{n+1}-u_{i, j-1}^{n+1}+u_{i, j+1}^{n}-u_{i, j-1}^{n}\right) \\
= & \frac{1}{2(\Delta y)^{2}}\left(u_{i, j-1}^{n+1}-2 u_{i, j}^{n+1}+u_{i, j+1}^{n+1}+u_{i, j-1}^{n}-2 u_{i, j}^{n}+u_{i, j+1}^{n}\right) \\
& +\frac{1}{2}\left(\theta_{i, j}^{n+1}+\theta_{i, j}^{n}\right)-\frac{1}{2} M\left(u_{i, j}^{n+1}+u_{i, j}^{n}\right), \\
\frac{1}{\Delta t}( & \left.\theta_{i, j}^{n+1}-\theta_{i, j}^{n}\right)+\frac{1}{2 \Delta x} u_{i, j}^{n}\left(\theta_{i, j}^{n+1}-\theta_{i-1, j}^{n+1}+\theta_{i, j}^{n}-\theta_{i-1, j}^{n}\right) \\
& +\frac{1}{4 \Delta y} v_{i, j}^{n}\left(\theta_{i, j+1}^{n+1}-\theta_{i, j-1}^{n+1}+\theta_{i, j+1}^{n}-\theta_{i, j-1}^{n}\right) \\
= & \frac{1}{2(\Delta y)^{2} \operatorname{Pr}}\left(\theta_{i, j-1}^{n+1}-2 \theta_{i, j}^{n+1}+\theta_{i, j+1}^{n+1}+\theta_{i, j-1}^{n}-2 \theta_{i, j}^{n}+\theta_{i, j+1}^{n}\right) \\
& -F\left(\frac{1}{2}\left(\theta_{i, j}^{n+1}+\theta_{i, j}^{n}\right)-1\right) .
\end{aligned}
$$

The coefficient appearing in difference equations are treated as constants. The finite-difference equations at every internal nodal point on a particular $n$-level constitute a tridiagonal system of equations. These equations are solved by using the Thomas algorithm [6]. Computations are carried out until the steady-state solution is assumed to have been reached when the absolute difference between the values of velocity as well as temperature at two consecutive time steps are less than $10^{-5}$ at all grid points.

\subsection{Stability analysis}

The stability analysis of the finite-difference equations that approximates the solution of heat transfer problems has been studied by Soundalgekar [13], Muthukumaraswamy and Ganesan [8], and Ganesan and Rani [3]. In this section, the von Neumann method is used to study the stability condition for the finite difference (3.1), (3.2), and (3.3).

The Fourier expansions for $u$ and $\theta$ are given by

$$
\begin{aligned}
& u=\Phi(t) e^{I \alpha x} e^{I \eta y}, \\
& \theta=\Psi(t) e^{I \alpha x} e^{I \eta y}
\end{aligned}
$$

where $I=\sqrt{-1}$. Substituting from (3.4) in (3.2) and (3.3). Under the assumptions that coefficients $u$ and $\theta$ are constant over any one step and denoting the values after one time step by $\Phi^{\prime}$ and $\Psi^{\prime}$, we may get that, 
72 Radiation effects on unsteady free-convection flow

after simplification,

$$
\begin{aligned}
\frac{\Phi^{\prime}-\Phi}{\Delta t} & +\frac{u}{2 \Delta x}\left(\Phi^{\prime}+\Phi\right)\left(1-e^{-I \alpha \Delta x}\right)+\frac{v}{2 \Delta y}\left(\Phi^{\prime}+\Phi\right)(I \sin \eta \Delta y) \\
& =\frac{1}{2}\left(\Psi^{\prime}+\Psi\right)-\frac{M}{2}\left(\Phi^{\prime}+\Phi\right)+\left(\Phi^{\prime}+\Phi\right) \frac{(\cos \eta \Delta y-1)}{\Delta y^{2}}, \\
\frac{\Psi^{\prime}-\Psi}{\Delta t} & +\frac{u}{2 \Delta x}\left(\Psi^{\prime}+\Psi\right)\left(1-e^{-I \alpha \Delta x}\right)+\frac{v}{2 \Delta y}\left(\Psi^{\prime}+\Psi\right)(I \sin \eta \Delta y) \\
& =\frac{1}{\operatorname{Pr}}\left(\Psi^{\prime}+\Psi\right) \frac{(\cos \eta \Delta y-1)}{\Delta y^{2}}-F\left(\frac{\Psi^{\prime}+\Psi}{2}-1\right) .
\end{aligned}
$$

These equations can be written as

$$
\begin{aligned}
& (1+A) \Phi^{\prime}=(1-A) \Phi+\frac{1}{2} \Delta t\left(\Psi^{\prime}+\Psi\right) \\
& (1+B) \Phi^{\prime}=(1-B) \Phi+F \Delta t
\end{aligned}
$$

where

$$
\begin{aligned}
& A=\frac{u}{2 \Delta x} \Delta t\left(1-e^{-I \alpha \Delta x}\right)+\frac{v}{2 \Delta y} \Delta t(I \sin \eta \Delta y)+\frac{M}{2} \Delta t-\frac{\Delta t}{\operatorname{Pr}} \frac{(\cos \eta \Delta y-1)}{\Delta y^{2}} \\
& B=\frac{u}{2 \Delta x} \Delta t\left(1-e^{-I \alpha \Delta x}\right)+\frac{v}{2 \Delta y} \Delta t(I \sin \eta \Delta y)+\frac{F}{2} \Delta t-\frac{\Delta t}{\operatorname{Pr}} \frac{(\cos \eta \Delta y-1)}{\Delta y^{2}}
\end{aligned}
$$

Equation (3.6) can be written in a matrix form as

$$
\left(\begin{array}{c}
\Phi^{\prime} \\
\Psi^{\prime}
\end{array}\right)=\left(\begin{array}{cc}
\frac{1-A}{1+A} & \frac{\Delta t}{(1+A)(1+B)} \\
0 & \frac{1-B}{1+B}
\end{array}\right)\left(\begin{array}{c}
\Phi \\
\Psi
\end{array}\right)+\left(\begin{array}{c}
\frac{F \Delta t^{2}}{2(1+A)(1+B)} \\
\frac{F \Delta t}{(1+B)}
\end{array}\right)
$$

For stability of finite-difference scheme, the modulus of each eigenvalue of the amplification matrix must not exceed unity. The eigenvalues of the amplification matrix are $(1-A) /(1+A)$ and $(1-B) /(1+B)$. Considering $u$ everywhere to be nonnegative and $v$ everywhere to be nonpositive, we get that

$$
A=2 a \sin ^{2}\left(\alpha \frac{\Delta x}{2}\right)+2 c \sin ^{2}\left(\eta \frac{\Delta y}{2}\right)+\frac{M}{2} \Delta t+I(a \sin \alpha \Delta x+b \sin \eta \Delta y)
$$


where

$$
a=\frac{u \Delta t}{2 \Delta x}, \quad b=\frac{|v| \Delta t}{2 \Delta y}, \quad c=\frac{\Delta t}{\Delta y^{2}} .
$$

Since the real part of $A$ is always greater than or equal to zero, $\mid(1-$ $A) /(1+A) \mid \leq 1$. Similarly, $|(1-B) /(1+B)| \leq 1$. Therefore, the scheme is unconditionally stable. The local truncation error is $O\left(\Delta t^{2}+\Delta y^{2}+\Delta x\right)$ and it tends to zero as $\Delta t, \Delta y$, and $\Delta x$ tend to zero. Hence, the scheme is compatible, and the stability and compatibility ensure convergence [6].

\section{The local skin-friction and heat transfer}

Knowing the velocity and temperature profiles, it is customary to study skin friction and Nusselt number in their transient and steady-state conditions.

The local, as well as average, skin friction and Nusselt number in terms of dimensionless quantities are given by [14]

$$
\begin{aligned}
\tau_{x} & =\left.\mathrm{Gr}^{3 / 4} \frac{\partial u}{\partial y}\right|_{y=0} \\
\bar{\tau} & =\left.\mathrm{Gr}^{3 / 4} \int_{0}^{1} \frac{\partial u}{\partial y}\right|_{y=0} d x, \\
\mathrm{Nu}_{x} & =-\frac{x \mathrm{Gr}^{1 / 4} \partial \theta /\left.\partial y\right|_{y=0}}{\left.\theta\right|_{y=0}} \\
\overline{\mathrm{Nu}} & =-\mathrm{Gr}^{1 / 4} \int_{0}^{1} \frac{\partial \theta /\left.\partial y\right|_{y=0}}{\left.\theta\right|_{y=0}} d x .
\end{aligned}
$$

The derivatives involved in (4.1) are evaluated using the following fivepoint approximation formula

$$
\left.\frac{\partial u}{\partial y}\right|_{y=0}=\frac{-17 u_{i, 0}^{n}+24 u_{i, 1}^{n}-12 u_{i, 2}^{n}+8 u_{i, 3}^{n}-3 u_{i, 4}^{n}}{12 \Delta y},
$$

and integrals are evaluated using Newton cotes formula.

\section{Results and discussions}

In order to assess the accuracy of our computed results, our results for steady-state values of the velocity and temperature was compared to those of the curves computed by Takhar et al. [14] for values of 
74 Radiation effects on unsteady free-convection flow

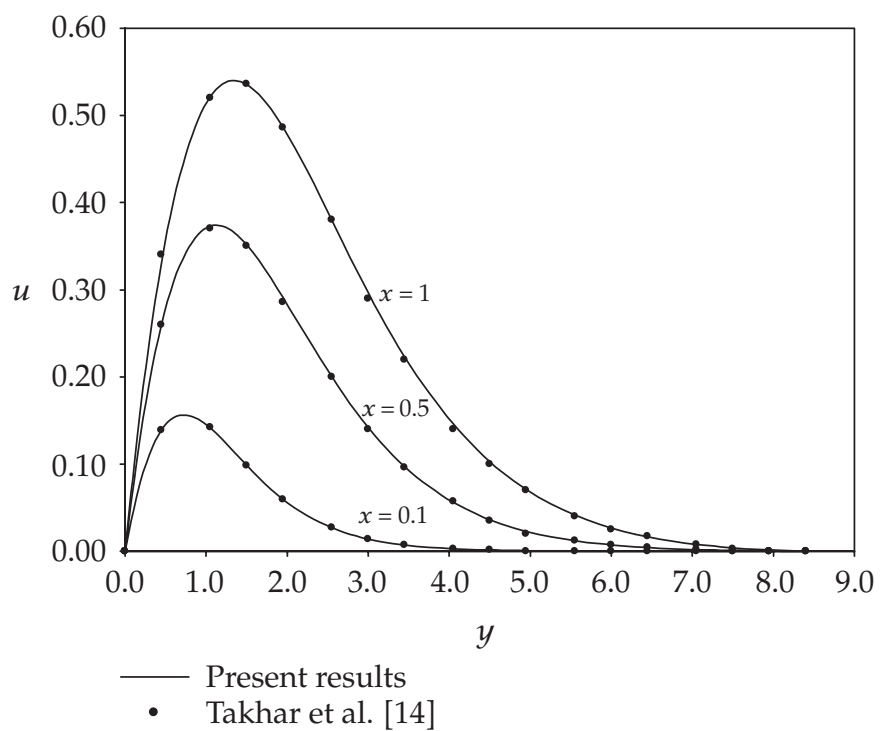

FIGURE 4.1. Comparison of steady-state velocity profiles at different values of $x$.

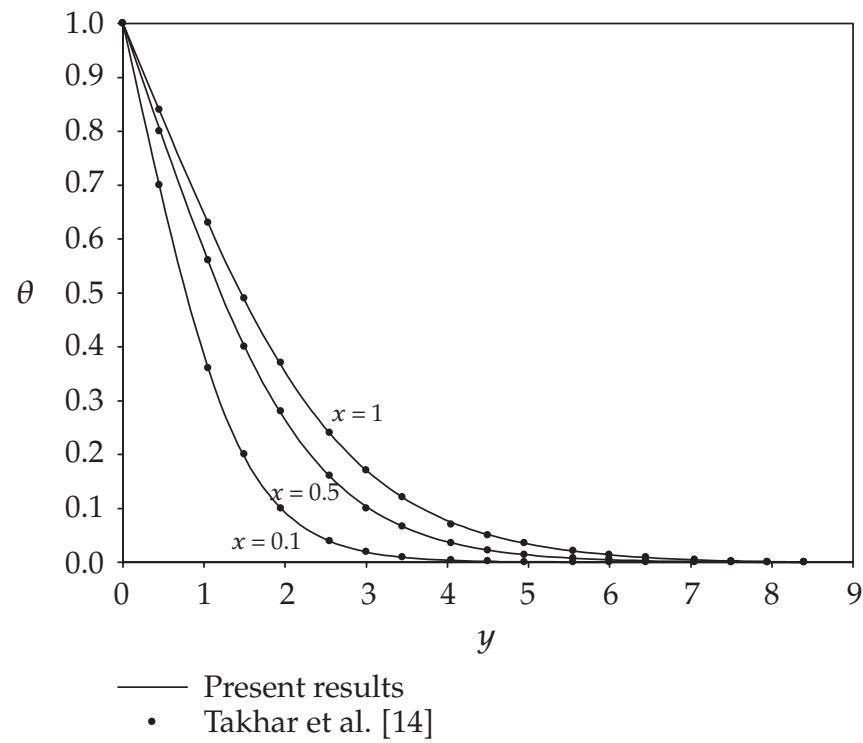

FIGURE 4.2. Comparison of steady-state temperature profiles at different values of $x$. 


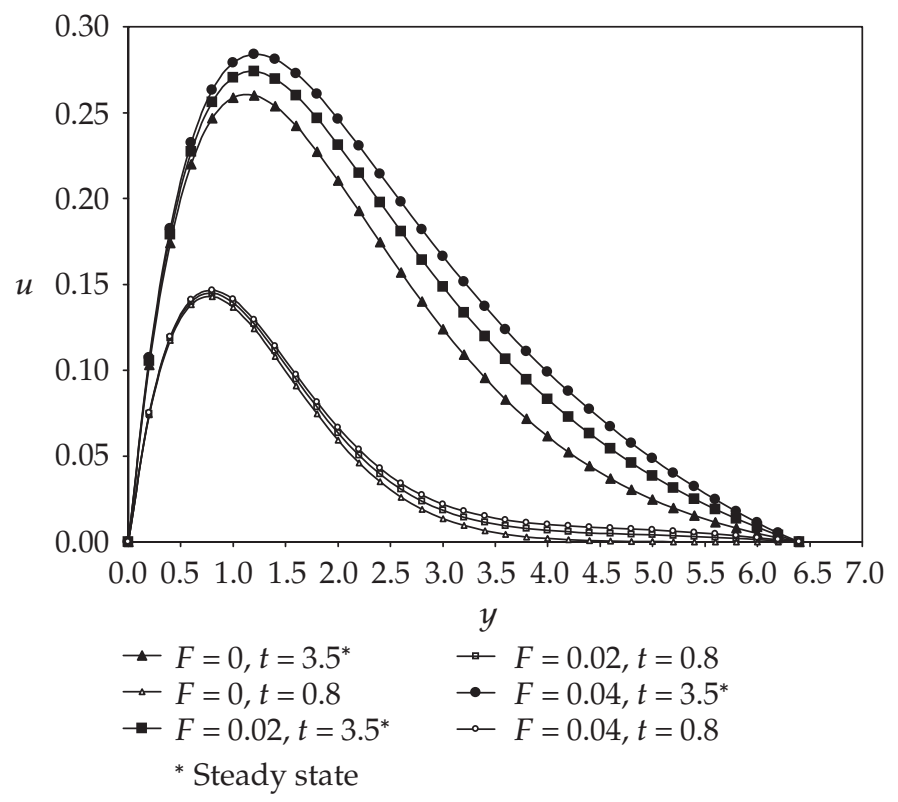

FiguRE 5.1. Transient velocity profiles for the different values of $F$ and for the values $x=1, M=1, m=1$, and $\operatorname{Pr}=0.7$.

$x=0.1,0.5,1.0, M=0, \operatorname{Pr}=0.7, F=0$, and $m=0$. These are plotted in Figures 4.1 and 4.2. It was observed that our results agree very well with those of Takhar et al. [14].

In our analysis, it was observed that radiation does affect the transient velocity and temperature field of free-convection flow of an electrically conducting fluid near a semi-infinite vertical plate with variable surface temperature in the presence of a transverse magnetic field.

The effect of radiation parameter $F$ on the transient velocity and temperature are shown in Figures 5.1 and 5.2, and it is observed that the transient velocity and temperature increase as the radiation parameter $F$ increases. This result qualitatively agrees with expectations since the effect of radiation and surface temperature are to increase the rates of energy transport to the fluid, thus increasing the temperature of the fluid.

Also, it is clearly shown that the transient velocity decreases with increasing the magnetic field parameter $M$; the Lorentz force, which opposes the flow, also increases and leads to enchanted deceleration of the flow. This conclusion meets the logic that the magnetic field exerts a retarding force on the free-convection flow. Figure 5.3 describes the behavior of transient velocity with changes in the values of the magnetic field parameter $M$. The effects of the magnetic field parameter $M$ on the heat 
76 Radiation effects on unsteady free-convection flow

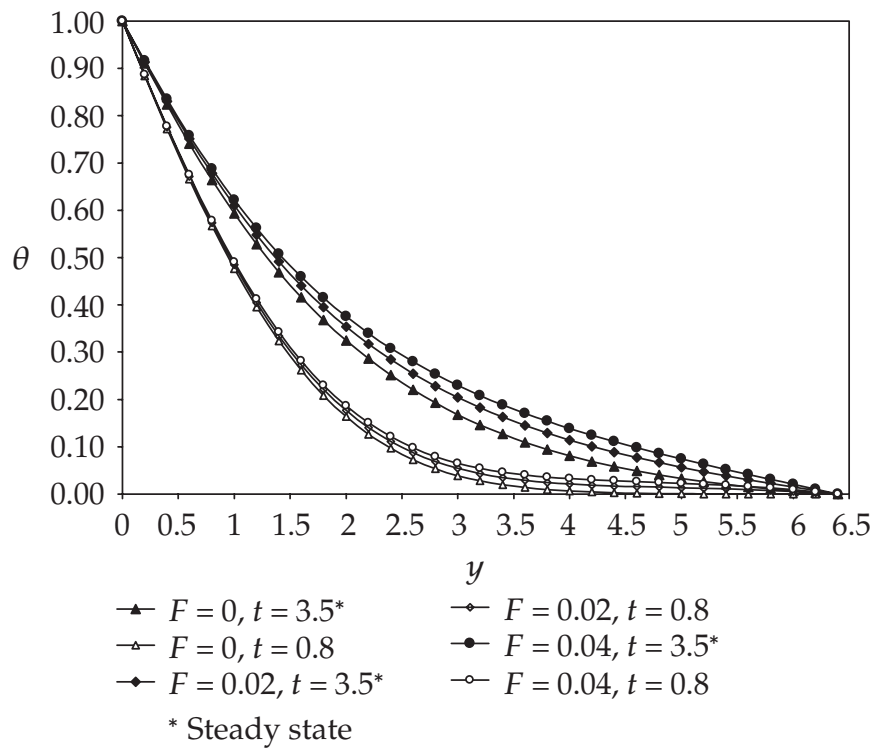

FIGURE 5.2. Transient temperature profiles for the different values of $F$ and for the values $x=1, m=1, M=1$, and $\operatorname{Pr}=0.7$.

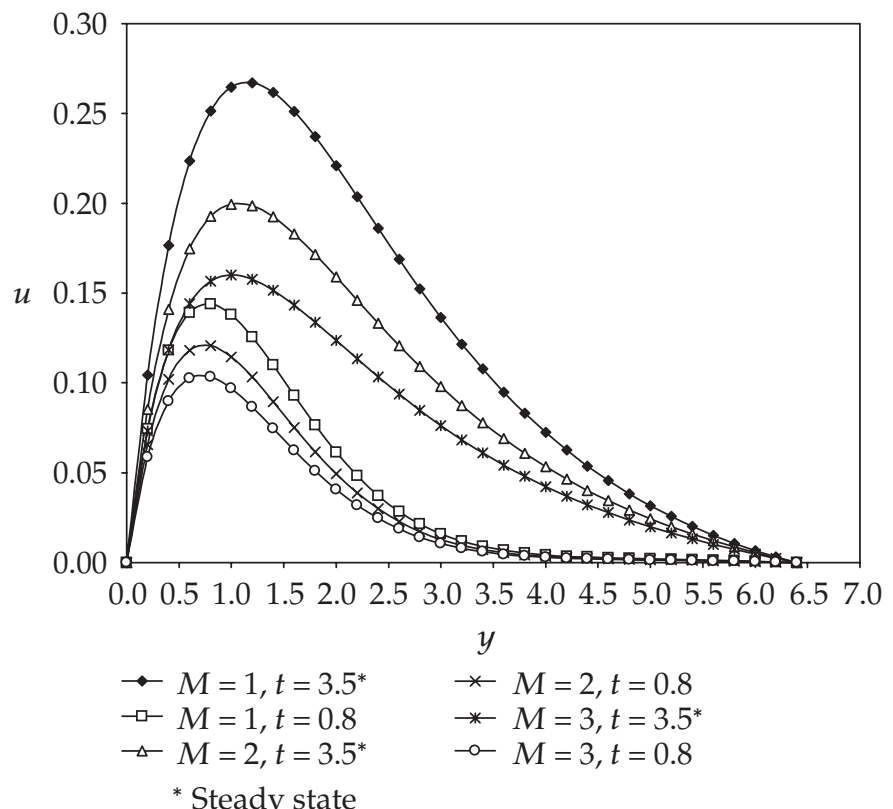

FIGURE 5.3. Transient velocity profiles for the different values of $M$ and for the values $x=1, F=0.01, m=1$, and $\operatorname{Pr}=0.7$. 


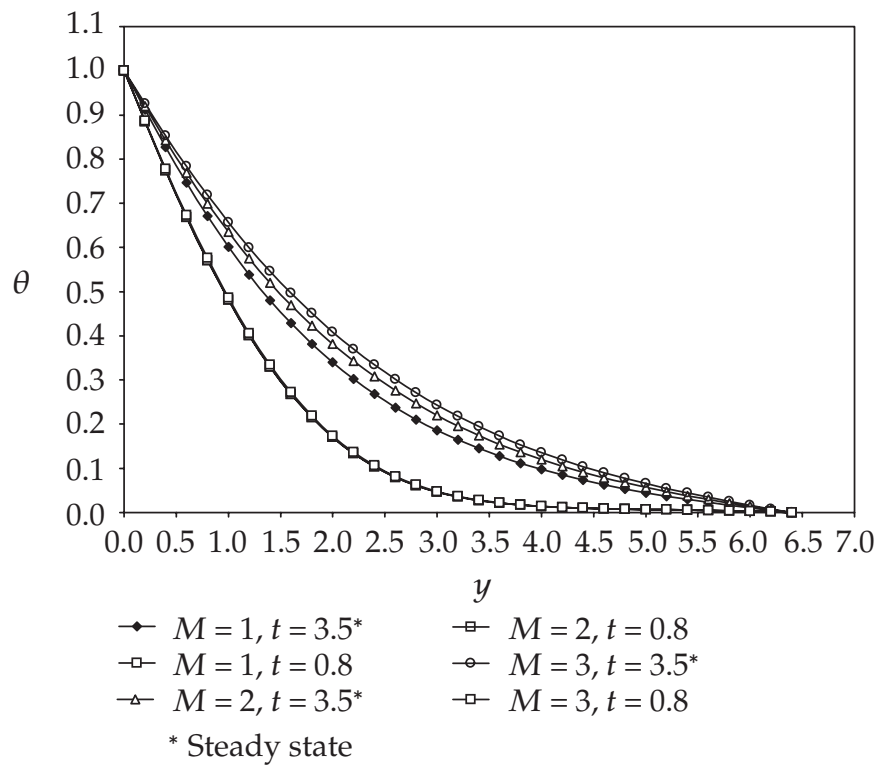

FIGURE 5.4. Transient temperature profiles for the different values of $M$ and for the values $x=1, F=0.01, m=1$, and $\operatorname{Pr}=0.7$.

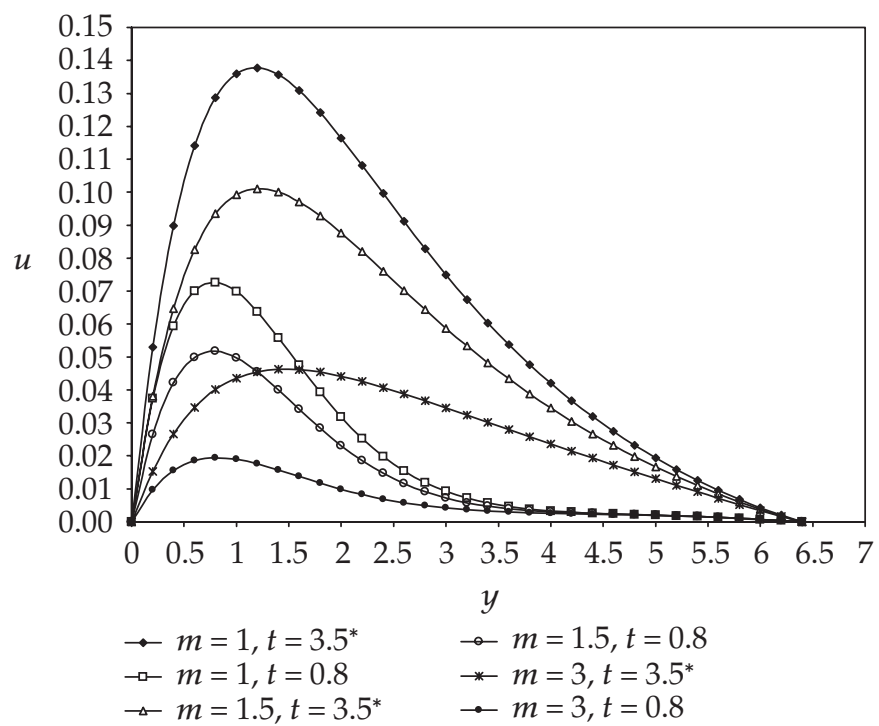

* Steady state

FIGURE 5.5. Transient velocity profiles for the different values of $m$ and for the values $x=0.5, F=0.01, M=1$, and $\operatorname{Pr}=0.7$. 
78 Radiation effects on unsteady free-convection flow

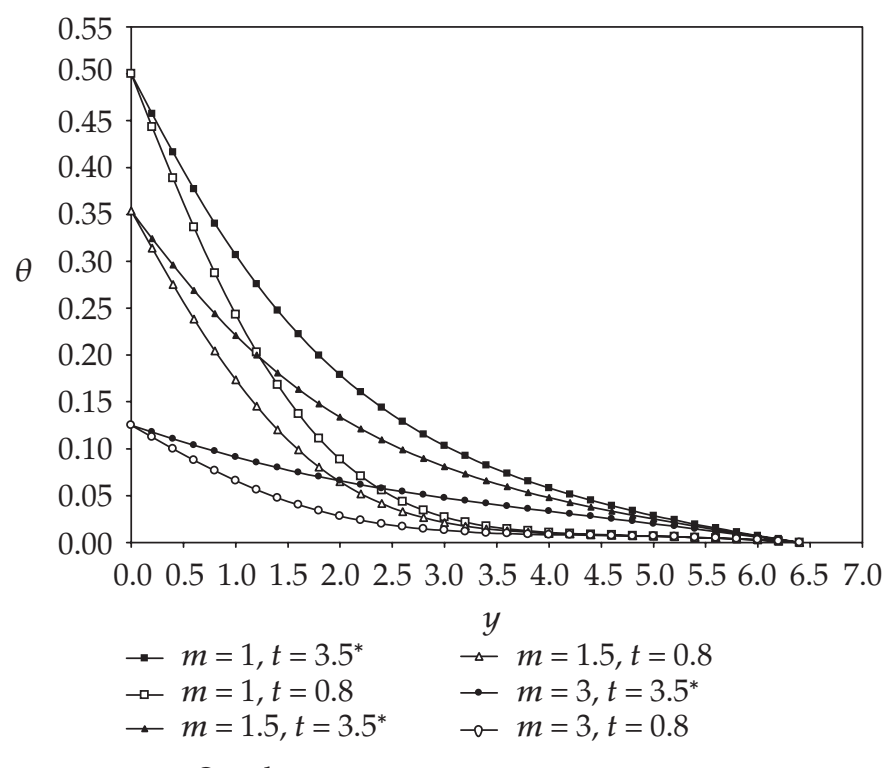

* Steady state

FIGURE 5.6. Transient temperature profiles for the different values of $m$ and for the values $x=0.5, F=0.01, M=1$, and $\operatorname{Pr}=0.7$.

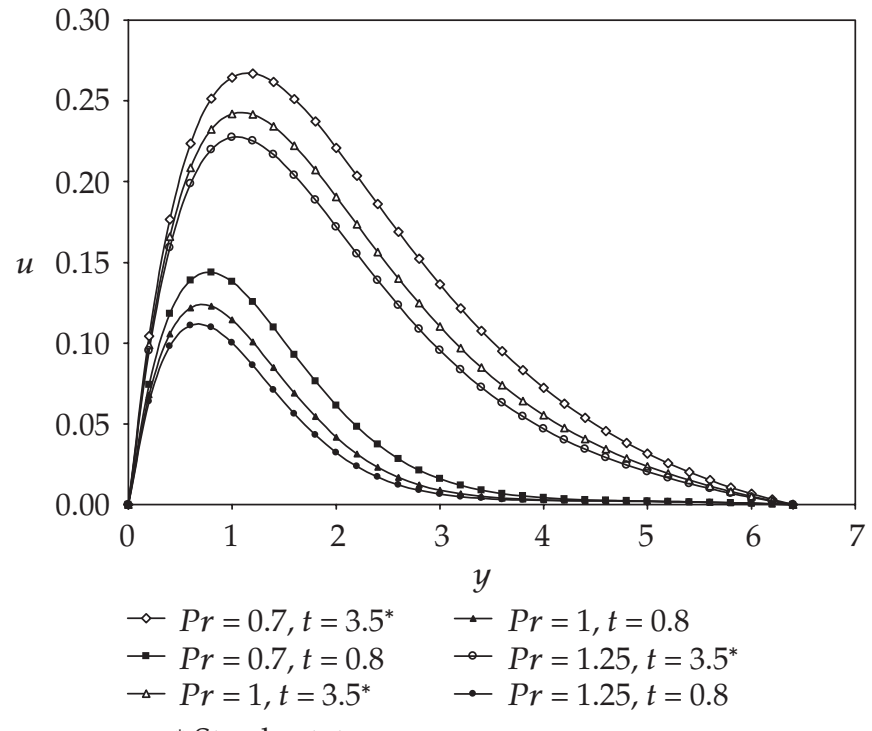

* Steady state

FIGURE 5.7. Transient velocity profiles for the different values of $\operatorname{Pr}$ and the values $x=1, F=0.01, m=1$, and $M=1$. 


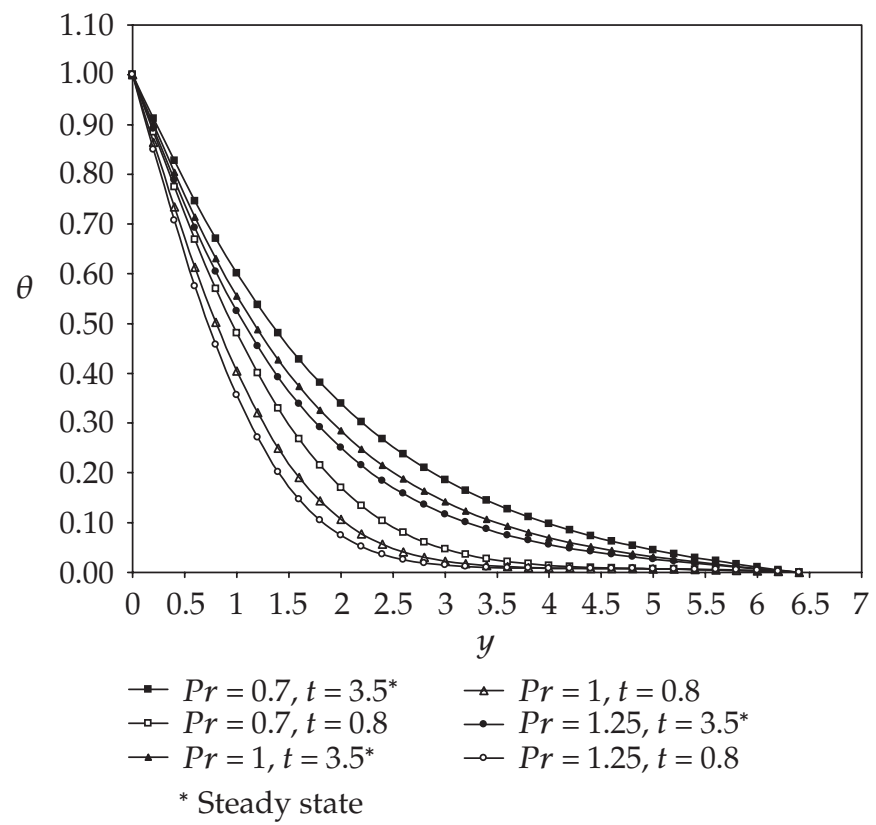

FigURE 5.8. Transient temperature profiles for the different values of $\operatorname{Pr}$ and the values $x=1, F=0.01, m=1$, and $M=1$.

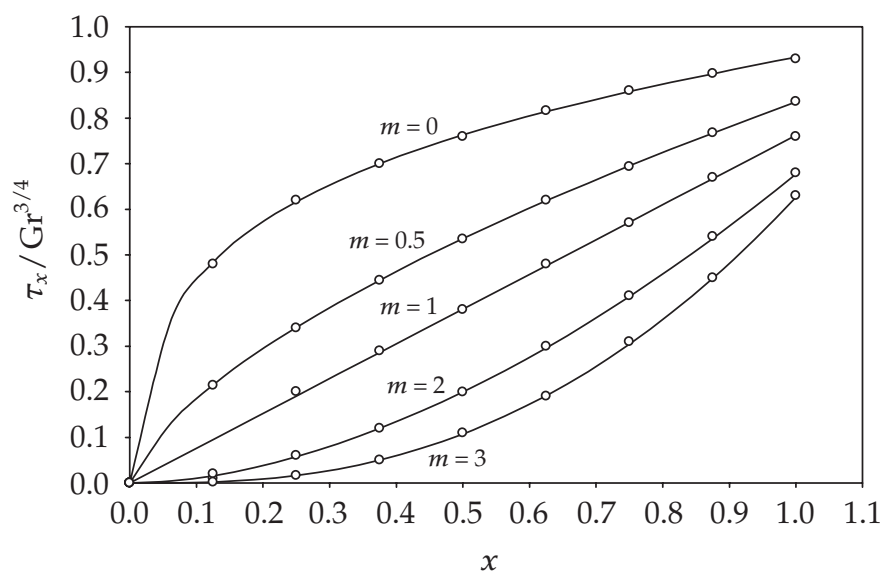

- Present results

- Takhar et al. [14]

FIGURE 5.9. Comparison of local skin friction. 
80 Radiation effects on unsteady free-convection flow

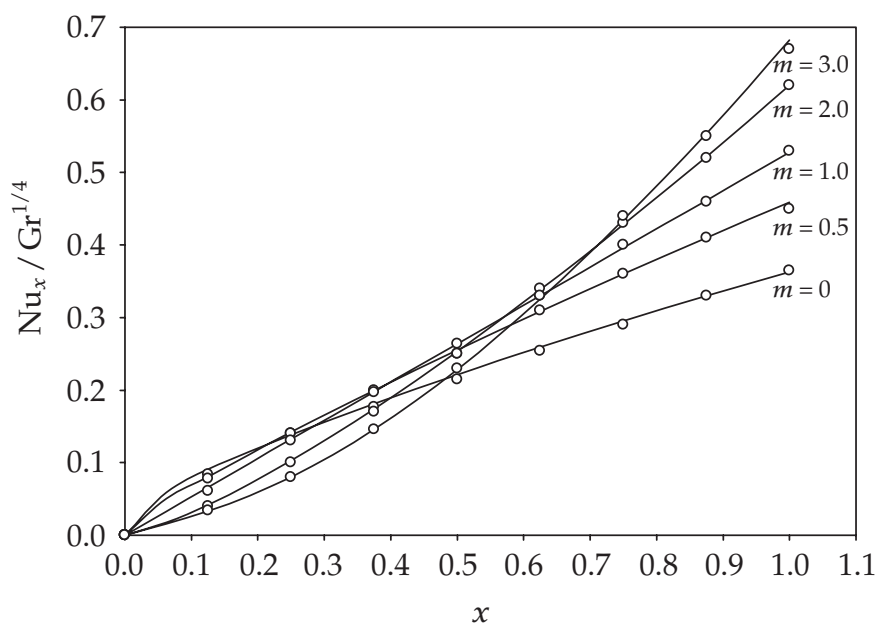

- Present results

- Takhar et al. [14]

FIGURE 5.10. Comparison of local Nusselt number.

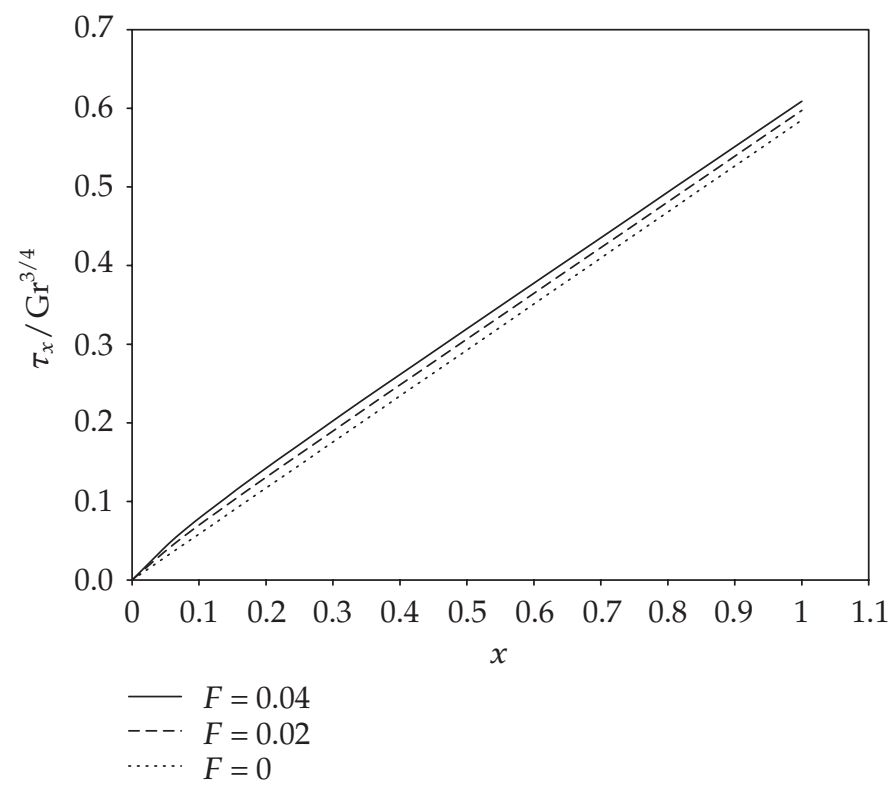

FIgURE 5.11. The effect of radiation parameter on local skin friction at $M=1, m=1$, and $\operatorname{Pr}=0.7$. 
M. A. Abd El-Naby et al. 81

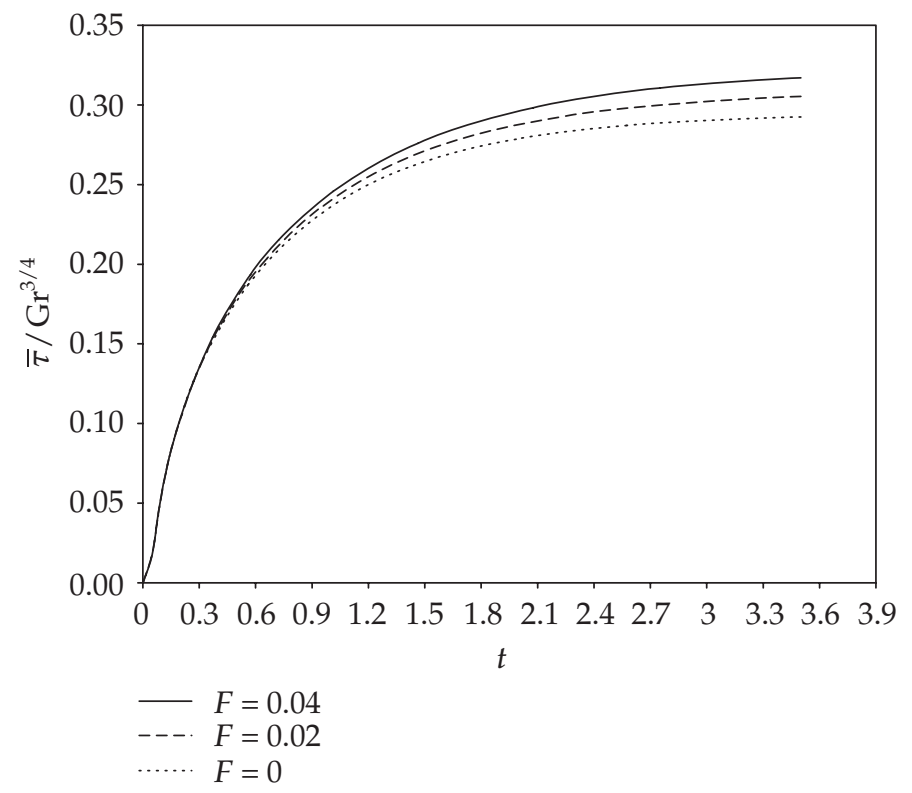

FIGURE 5.12. The effect of radiation parameter on average skin friction at $M=1, m=1$, and $\operatorname{Pr}=0.7$.

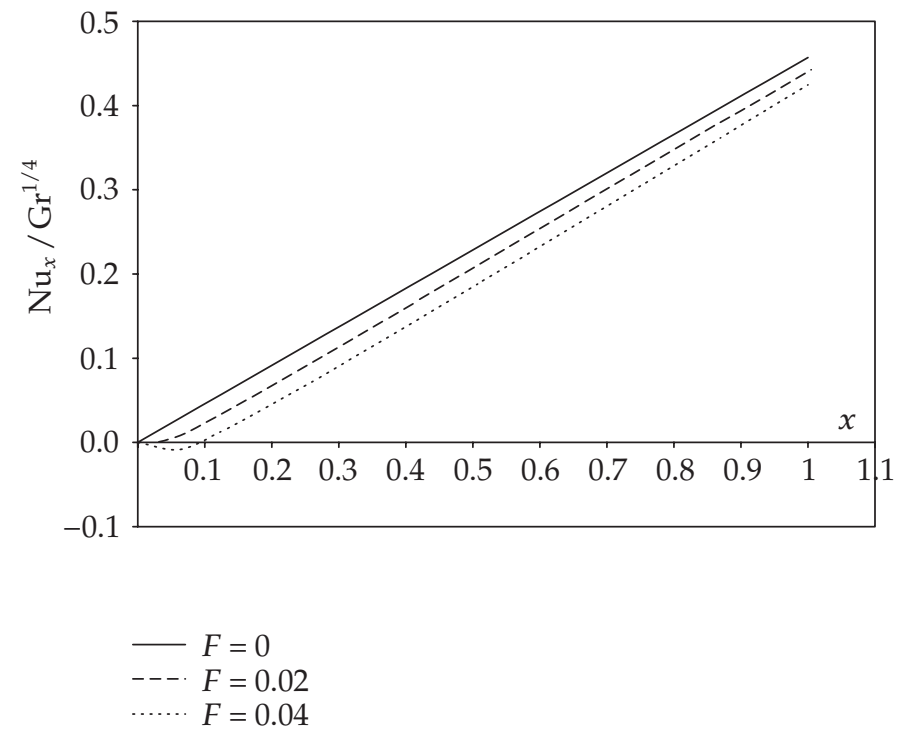

FIGURE 5.13. The effect of radiation parameter on local Nusselt number at $M=1, m=1$, and $\operatorname{Pr}=0.7$. 
82 Radiation effects on unsteady free-convection flow

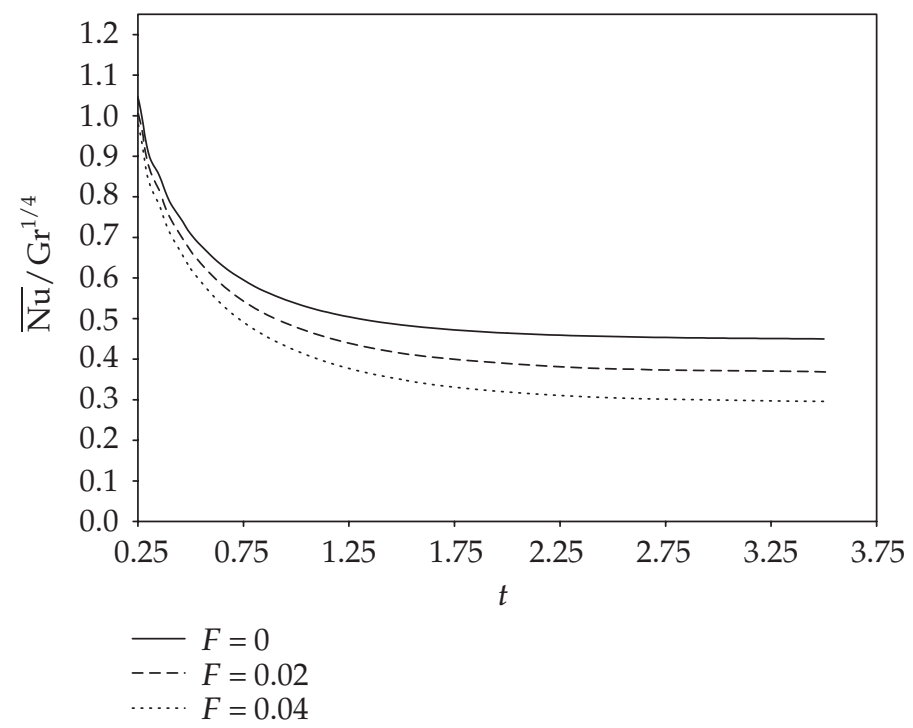

FIGURE 5.14. The effect of radiation parameter on average Nusselt number at $M=1, m=1$, and $\operatorname{Pr}=0.7$.

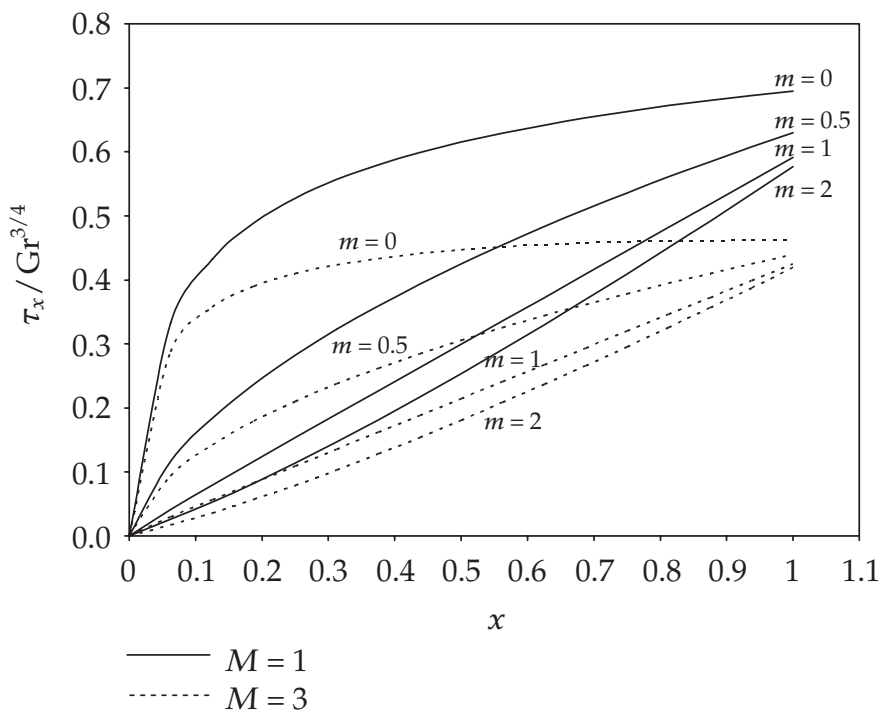

FigURE 5.15. The effect of $M$ and $m$ parameters on local skin friction at $F=0.01$ and $\operatorname{Pr}=0.7$. 


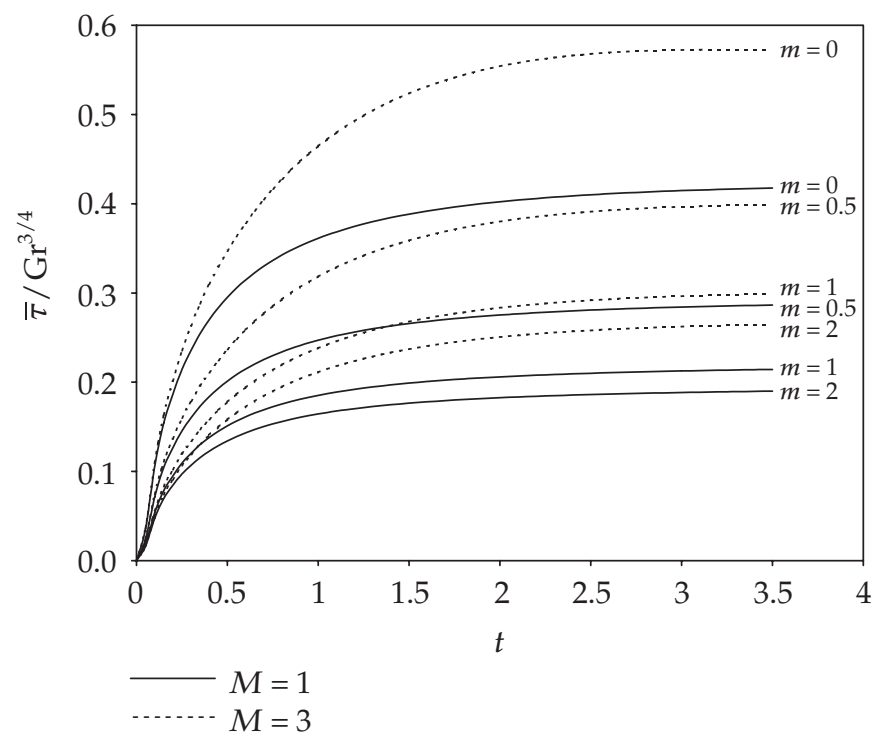

FIGURE 5.16. The effect of $M$ and $m$ parameters on average skin friction at $F=0.01$ and $\operatorname{Pr}=0.7$.

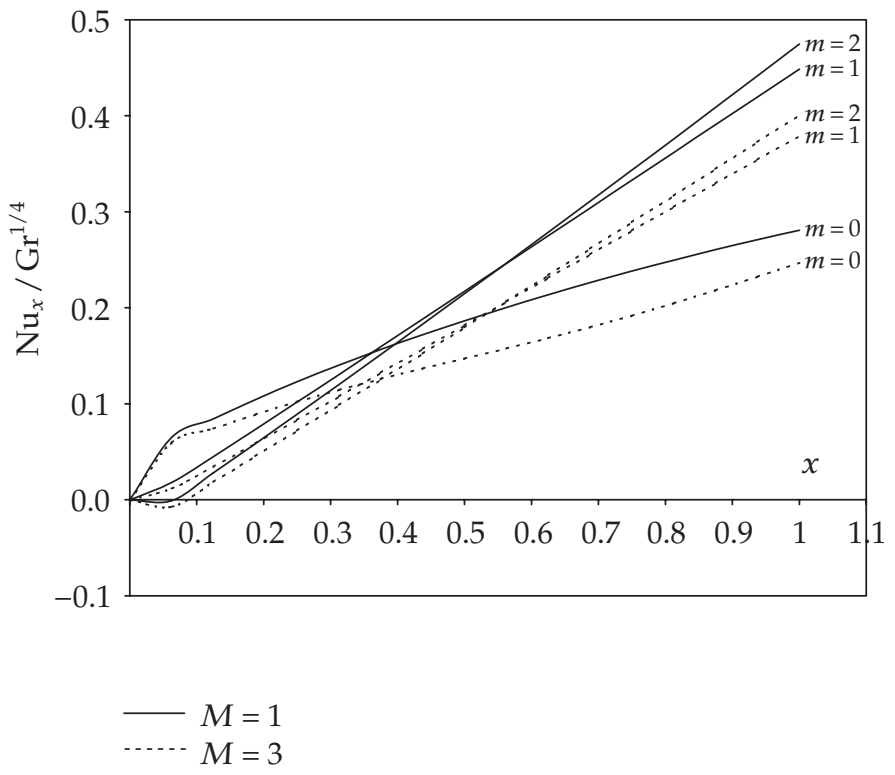

FIGURE 5.17. The effect of $M$ and $m$ parameters on local Nusselt number at $F=0.01$ and $\operatorname{Pr}=0.7$. 
84 Radiation effects on unsteady free-convection flow

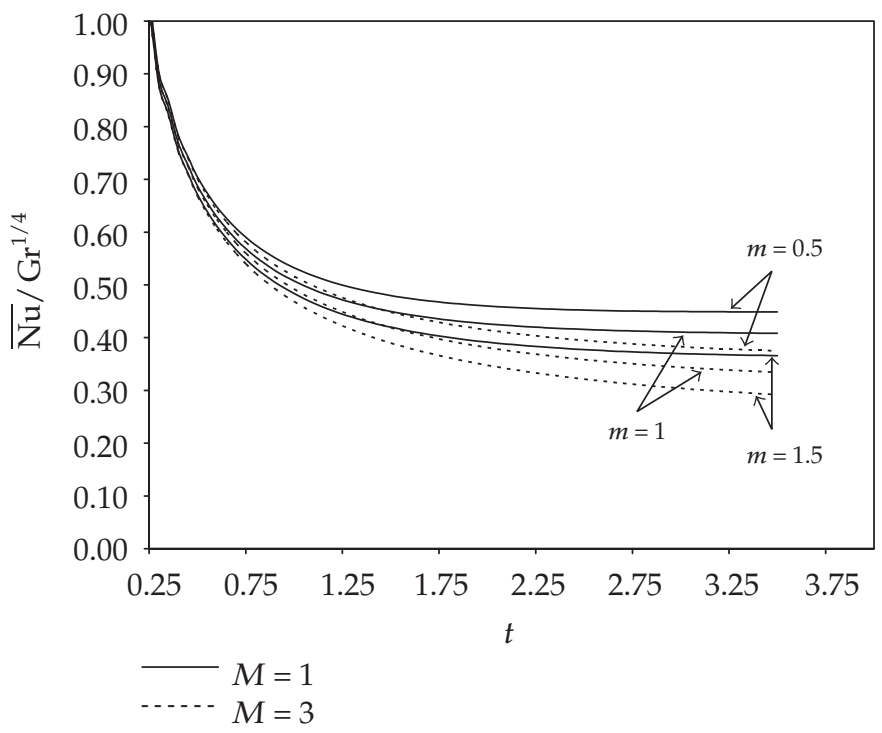

FIGURE 5.18. The effect of $M$ and $m$ parameters on average Nusselt number at $F=0.01$ and $\operatorname{Pr}=0.7$.

transfer are shown in Figure 5.4. It is observed that the temperature increases when $M$ parameters increase.

Transient velocity and temperature profiles are shown in Figures 5.5 and 5.6, respectively, with changes in the values of the " $m$ " parameter. Both velocity and temperature decrease as $m$ increases.

Figures 5.7 and 5.8 show the effect of "Pr" on transient velocity and temperature distribution. Both velocity and temperature decrease as Pr increases. This is in agreement with the physical fact that the thermal boundary layer thickness decreases with increasing Pr.

In the present paper, the numerical results of the local skin friction and local Nusselt number are in good agreement with the results of Takhar et al. [14] as shown in Figures 5.9 and 5.10.

The effect of radiation parameter $F$ on local skin friction, average skin friction, local Nusselt number, and average Nusselt number is shown in Figures 5.11, 5.12, 5.13, and 5.14. It is observed that the local and average skin frictions increase as $F$ increases. However, local and average Nusselt numbers decrease as $F$ increases.

Figures 5.15, 5.16, 5.17, and 5.18 show the effect of $M$ and $m$ parameters on local skin friction, average skin friction, local Nusselt number, and average Nusselt number, respectively. It is observed that the local and average skin friction and average Nusselt number decrease as $m$ increases. The local Nusselt number increases as $m$ increases. However, it 
is observed that the above trend is reversed near the leading edge. The local skin friction, local Nusselt number, and average Nusselt number decrease as $M$ increases. However, average skin friction increases as $M$ increases.

\section{References}

[1] A. C. Cogley, W. G. Vincenti, and S. E. Gilles, Differential approximation for radiation transfer in a nongray near equilibrium, AIAA J. 6 (1968), 551-553.

[2] E. M. A. Elbashbeshy, Radiation effect on heat transfer over a stretching surface, Canad. J. Phys. 78 (2000), 1107-1112.

[3] P. Ganesan and H. P. Rani, Transient natural convection flow over vertical cylinder with variable surface temperatures, Forsch. Ingenieurwesen 66 (2000), $11-16$.

[4] A. Y. Ghaly and E. M. E. Elbarbary, Radiation effect on MHD free-convection flow of a gas at a stretching surface with a uniform free stream, J. Appl. Math. 2 (2002), no. 2, 93-103.

[5] M. Y. Gokhale, Magnetohydrodynamic transient-free convection past a semiinfinite vertical plate with constant heat flux, Canad. J. Phys. 69 (1991), 14511453.

[6] J. D. Hoffman, Numerical Methods for Engineers and Scientists, McGraw-Hill, New York, 1992.

[7] S. Kakac and Y. Yener, Convective Heat Transfer, CRC Press, Florida, 1995.

[8] R. Muthukumaraswamy and P. Ganesan, Unsteady flow past an impulsive by started vertical plate with heat and mass transfer, Heat and Mass Transfer 34 (1998), 187-193.

[9] W. M. Rohsenow, J. P. Hartnett, and Y. I. Cho (eds.), Handbook of Heat Transfer, McGraw-Hill, New York, 1998.

[10] M. F. Roming, The influence of electric and magnetic fields on heat transfer to electrically conducting fluid, Advances in Heat Transfer (T. F. Irvine and J. P. Hartnett, eds.), vol. 1, Academic Press, 1964, pp. 286-354.

[11] M. A. Seddeek, Thermal radiation and buoyancy effects on MHD free convective heat generating flow over an accelerating permeable surface with temperaturedependent viscosity, Canad. J. Phys. 79 (2001), 725-732.

[12] T. M. Shih, Numerical Heat Transfer, Series in Computational Methods in Mechanics and Thermal Sciences, Hemisphere, Washington, DC, 1984.

[13] V. M. Soundalgekar, Finite difference analysis of transient free convection with mass transfer on an isothermal vertical flat plate, Internat. J. Engrg. Sci. 19 (1981), 757-770.

[14] H. S. Takhar, P. Ganesan, K. Ekambavahar, and V. M. Soundalgekar, Transient free convection past a semi-infinite vertical plate with variable surface temperature, Internat. J. Numer. Methods Heat Fluid Flow 7 (1997), 280-296.

[15] H. S. Takhar, R. S. R. Gorla, and V. M. Soundalgekar, Radiation effects on MHD free convection flow of a gas past a semi-infinite vertical plate, Internat. J. Numer. Methods Heat Fluid Flow 6 (1996), 77-83. 
86 Radiation effects on unsteady free-convection flow

M. A. Abd El-Naby: Department of Mathematics, Faculty of Education, Ain Shams University, Roxy, Heliopolis, Cairo, Egypt.

Elsayed M. E. Elbarbary: Department of Mathematics, Faculty of Education, Ain Shams University, Roxy, Heliopolis, Cairo, Egypt.

Nader Y. AbdElazem: Department of Mathematics, Faculty of Education, Ain Shams University, Roxy, Heliopolis, Cairo, Egypt. 


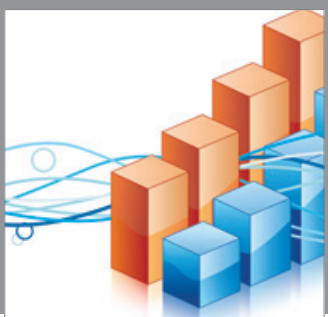

Advances in

Operations Research

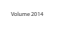

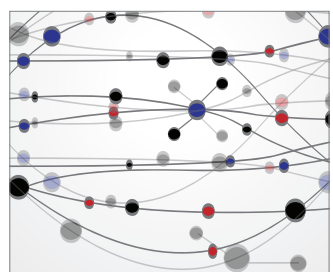

\section{The Scientific} World Journal
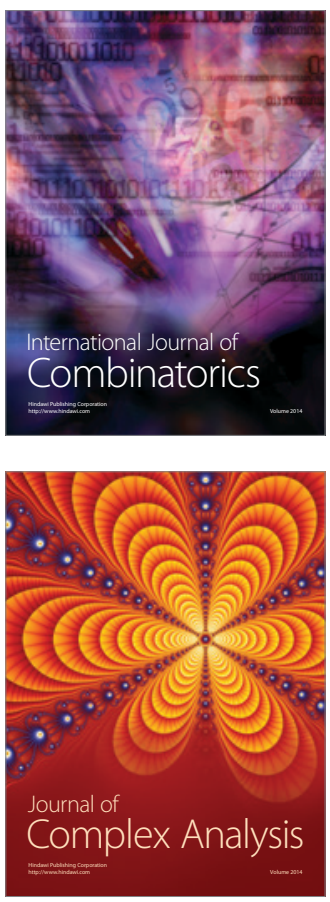

International Journal of

Mathematics and

Mathematical

Sciences
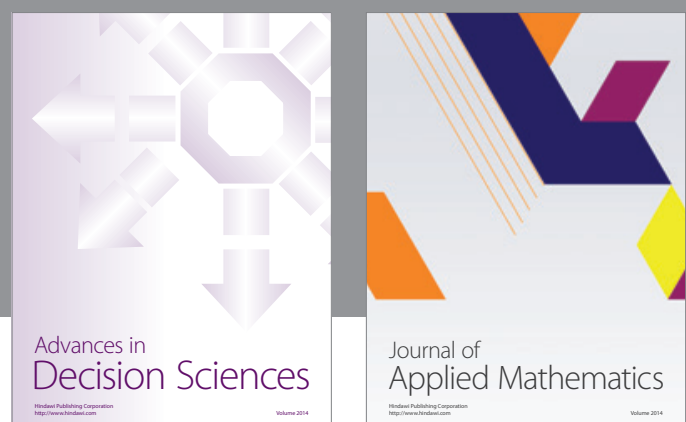

Journal of

Applied Mathematics
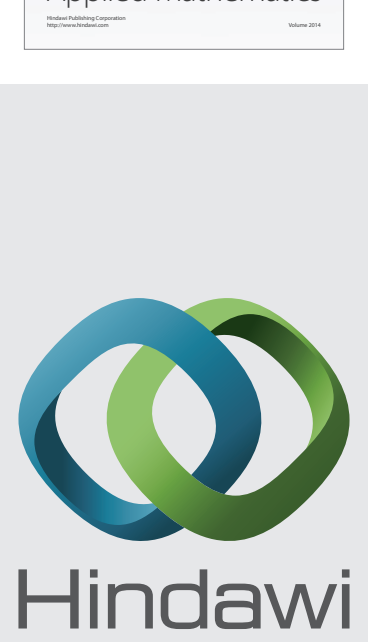

Submit your manuscripts at http://www.hindawi.com
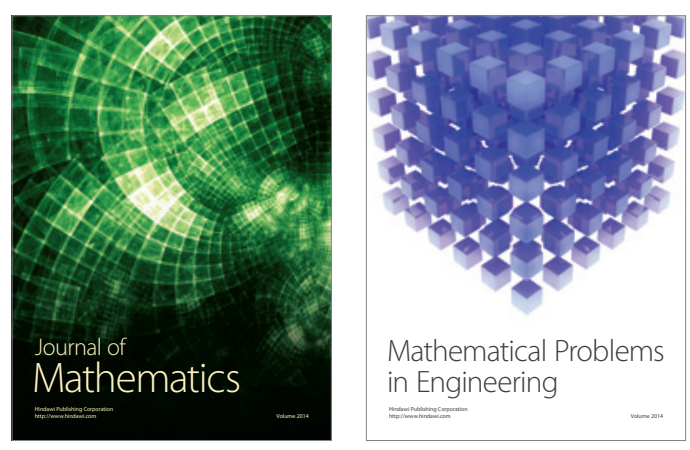

Mathematical Problems in Engineering
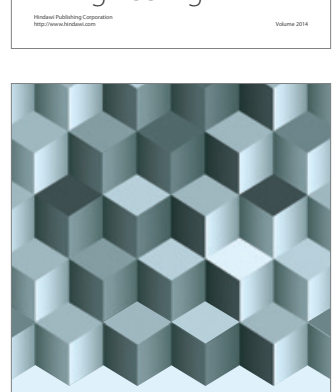

Journal of

Function Spaces
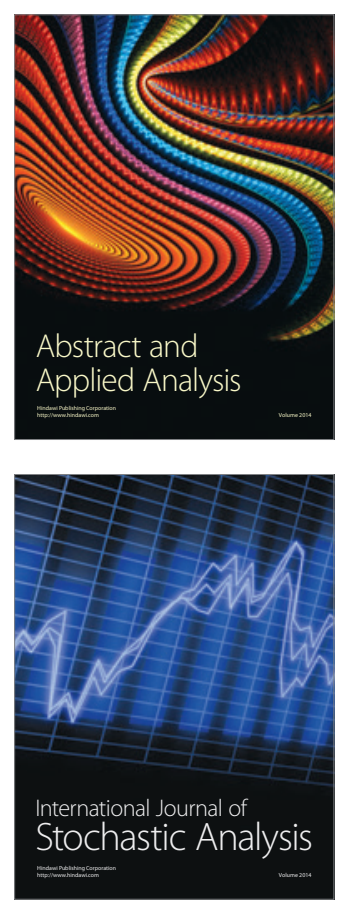

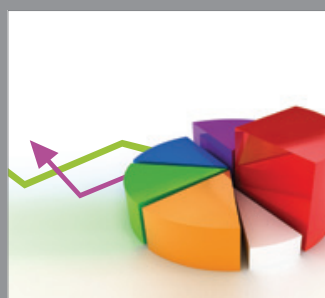

ournal of

Probability and Statistics

Promensencen
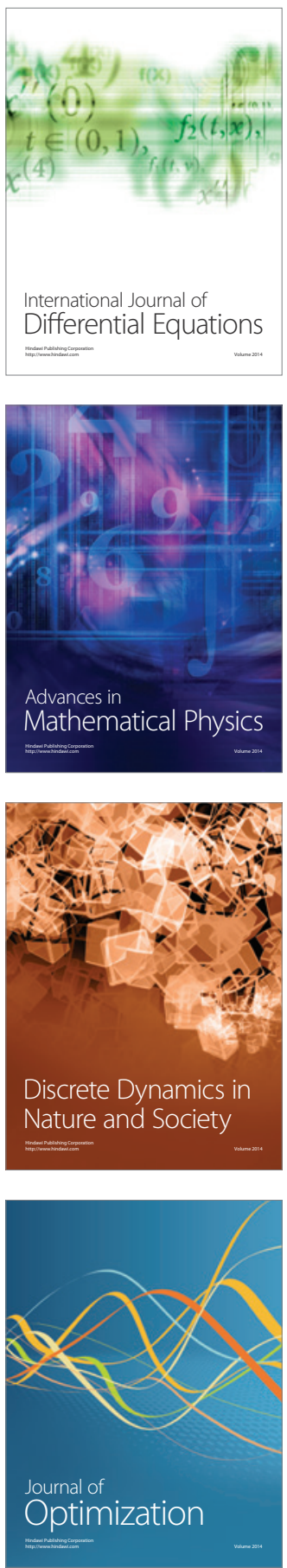